E3S Web of Conferences 1, 30002 (2013)

DOI: $10.1051 / \mathrm{e} 3$ sconf/20130130002

(C) Owned by the authors, published by EDP Sciences, 2013

\title{
Ancillary Benefits of Climate Policies for the Mitigation of Atmospheric Mercury Emissions
}

\author{
P. Rafaj ${ }^{1}$ and J. Cofala ${ }^{1}$ \\ ${ }^{1}$ International Institute for Applied Systems Analysis (IIASA), Mitigation of Air Pollution \& Greenhouse Gases Program, \\ A-2361 Laxenburg, Austria, rafaj@iiasa.ac.at
}

\begin{abstract}
This study provides an analysis of the impact of global climate policies on mercury emissions using the Greenhouse Gas and Air Pollution Interactions and Synergies (GAINS) model in the time horizon up to 2050. The time evolution of mercury emissions is based on projections of energy consumption provided by the Prospective Outlook for the Long term Energy System (POLES) model for a scenario without any global greenhouse gas mitigation efforts, and for a $2^{\circ} \mathrm{C}$ climate policy scenario, which assumes internationally coordinated action to mitigate climate change. Outcomes of the analysis are reported globally and for key world regions: EU-27, China, India and the US. The assessment takes into account current air pollution control legislation in each country. Scenario calculations for mercury emissions indicate significant scope for co-benefits made possible through climate policies. Atmospheric releases of mercury from anthropogenic sources under the global climate mitigation regime are reduced in 2050 by $45 \%$ when compared to the case without climate measures. Around one third of co-benefits for mercury emissions estimated world-wide in this study by 2050 are allocated to China. An annual Hg-abatement of about 800 tons is estimated for the coal combustion in power sector if the current air pollution legislation and climate policies are adopted in parallel.
\end{abstract}

Key words: Mercury emissions, Air pollution control, Climate policy, Co-benefits.

\section{Introduction}

The European Commission (EC) has made proposals for keeping climate change to manageable levels in its Communication "Limiting Global Climate Change to $2^{\circ}$ Celsius: The way ahead for 2020 and beyond" (CEC, 2007). The document proposed ambitious emission reduction pathways for greenhouse gases that the EU should pursue in the context of international climate change negotiations necessary to ensure that climate change does not cause temperatures to increase beyond $2{ }^{\circ} \mathrm{C}$.

At the same time, it is well recognized that addressing the climate change with a set of emission mitigation strategies might gain numerous positive side-effects, for example improved energy supply security, reduced environmental pressure, or smaller burden on human health (van Aardenne et al., 2010).

In this context, it is of a particular interest for national policy makers and climate negotiators to have an access to quantitative information on the size of potential co-benefits and synergies between abating climate change and other goals of sustainable development. This study describes results of detailed assessment of the impacts of future climate policies consistent with $\mathrm{EU} 2{ }^{\circ} \mathrm{C}$ target on the mercury $(\mathrm{Hg})$ emissions for key individual countries and regions, covering major sectors responsible for emissions of anthropogenic greenhouse gases (GHG) and mercury for the period after 2012, up to 2050.

\section{Materials and Methods}

\section{Modeling Framework}

Work reported here involves the linkage of the global POLES energy-system model with GAINS, which is a tool to quantify emission levels, costs and impacts of strategies to reduce both greenhouse gases and air pollutants (Amann et al., 2011). Based on activity projections provided by POLES, Hg-emissions scenarios have been developed in GAINS considering a full implementation of current national legislation (CLE) to control air pollution by 2030 , but not strengthening it further between 2030 and 2050.

Although the POLES inputs provide information on the time evolution of the energy sector until 2050 , there is 


\section{Baseline}



Mitigation

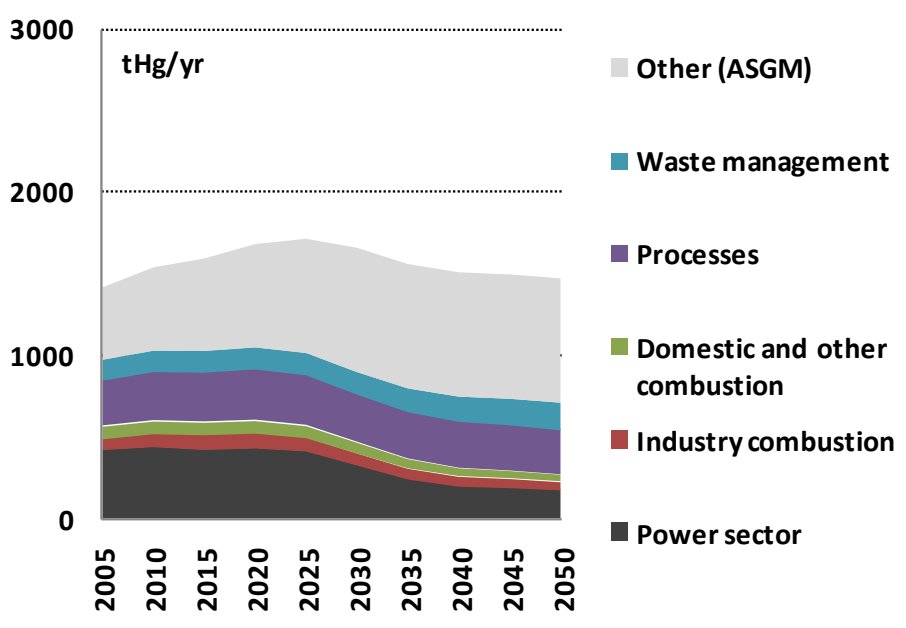

Fig. 1. Global mercury emission estimates for the Baseline and Mitigation scenarios for the period $2005-2050$ by sectors.
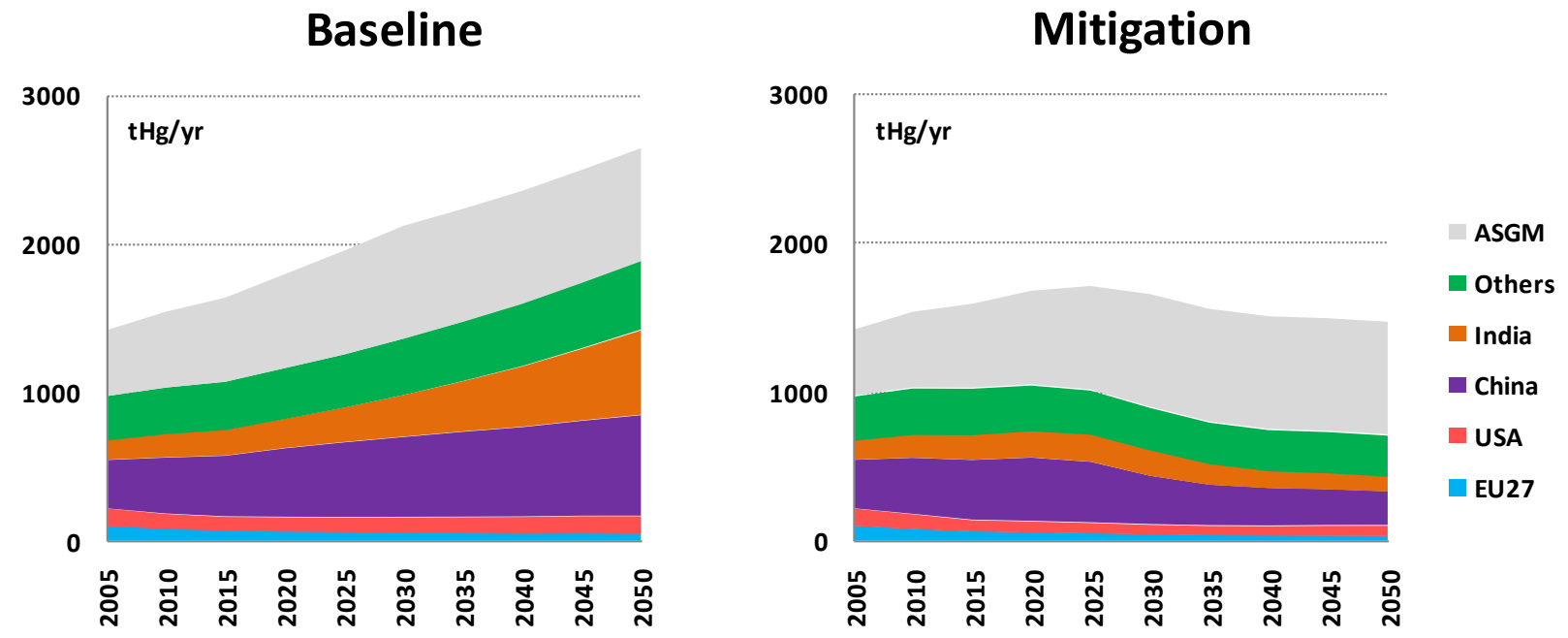

Fig. 2. Mercury emission estimates for the Baseline and Mitigation scenarios for the period 2005 - 2050 by regions.

a set of Hg-emission sources not covered directly by the energy model. Missing information has therefore been completed based on scenarios already available in GAINS or has been derived from relevant drivers, for example, GDP and population projections. This included extension of the model structure and derivation of sector-specific activities causing mercury emissions from industrial processes, metals smelting, artisanal small-scale gold mining (ASGM), waste treatment, etc.

\section{Scenarios}

Using the model linkage, two POLES scenarios have been implemented in GAINS and used for the impact calculation of climate change mitigation policies on Hg-emissions: a) Baseline scenario (BAS) that reflects unchanged governmental energy and climate policies, and b) Mitigation scenario (MIT) which assumes implementation of policies to limit the increase in average global temperatures to about $2^{\circ} \mathrm{C}$. Underlying drivers and assumptions behind the POLES energy projections are described in detail by Russ et al. (2009).

Air pollution control strategies adopted for calculation of $\mathrm{Hg}$-emissions are based on the most recent national legislation and environmental planning, i.e., policies that were in force or in the final stage of legislative process as of 2010 (Cofala et al. 2010). It is noted that the GAINS database contains information about numerous abatement technologies (or measures), applicable to a co-control of mercury and the traditional air pollutants, e.g., sulphur or particulates. In addition to the existing multipollutant framework of GAINS, 
$\mathrm{Hg}$-specific primary measures, such as sorbent injection, were assotiated with relevant sectors, for instance the waste incineration, or chlor-alkali production.

Finally, it is emphasised that the co-benefits of GHG mitigation policies for Hg-reductions emerge solely from the reconfiguration of the energy system, and not from more stringent air pollution emission control measures under a climate protection regime.

\section{Results and Discussion}

The implementation of two scenarios in GAINS results in trajectories for atmospheric mercury that combine short-term air pollution control policies with the long-term evolution of the global energy system driven by the climate mitigation objectives. Global Hg-emission estimates for the Baseline and Mitigation cases for the period 2005 - 2050 are compared in Figure 1. Globally, some reduction in $\mathrm{Hg}$-emissions between the two scenarios is apparent by 2020 but this is relatively small $(6 \%)$. In 2030 the change is more pronounced, with $22 \%$ less $\mathrm{Hg}$ emitted. In 2050, mercury emissions are reduced by nearly $1.2 \mathrm{kt} \mathrm{Hg}$ per annum, which corresponds to relative reductions over the Baseline of $45 \%$.

The largest relative reductions in $\mathrm{Hg}$-emissions are achieved in the power plant sector, with about $80 \%$ less mercury in 2050, related to the much reduced use of coal in the Mitigation scenario. There are also significant reductions from combustion in households and industry, while industrial process emissions are lower by 30\% in comparison to the Baseline levels in 2050. Emission estimates from ASGM are also shown in Figure 1, however, activities in this sector are based on extrapolation of current trends and are not affected by the climate targets.

There are significant differences in the projected $\mathrm{Hg}$ emissions by 2050 among the world regions. While the emissions decline or are stabilized in Europe and in the US towards the end of computation period, mercury releases are projected to increase for the fast growing economies of China and India. Since the Baseline scenario assumes a rapid grow in the coal combustion in both countries, the synergetic effect of GHG abatement towards reduction in $\mathrm{Hg}$ emissions is larger as compared to other regions. As shown in Figure 2, mercury emissions reductions in the Mitigation scenario for China and India induced through the reconfiguration of the energy system by 2050 are estimated at about $70 \%$ and $80 \%$, respectively. Significant drop in mercury emissions in India is associated with the CLE control strategy assuming a limited implementation of air pollution measures that co-control $\mathrm{Hg}$ releases.

The relation between $\mathrm{CO}_{2}$ mitigation and $\mathrm{Hg}$ emissions is further depicted in Figure 3, showing the emissions reductions relative to the year 2005 for both Baseline and Mitigation cases. In the Baseline, $\mathrm{CO}_{2}$ emissions are reduced or stabilized in EU-27 and in US, while the regions of China and India experience a rapid growth in $\mathrm{CO}_{2}$ emissions up to 2050, resulting in the

\section{Hg emissions relative to 2005}

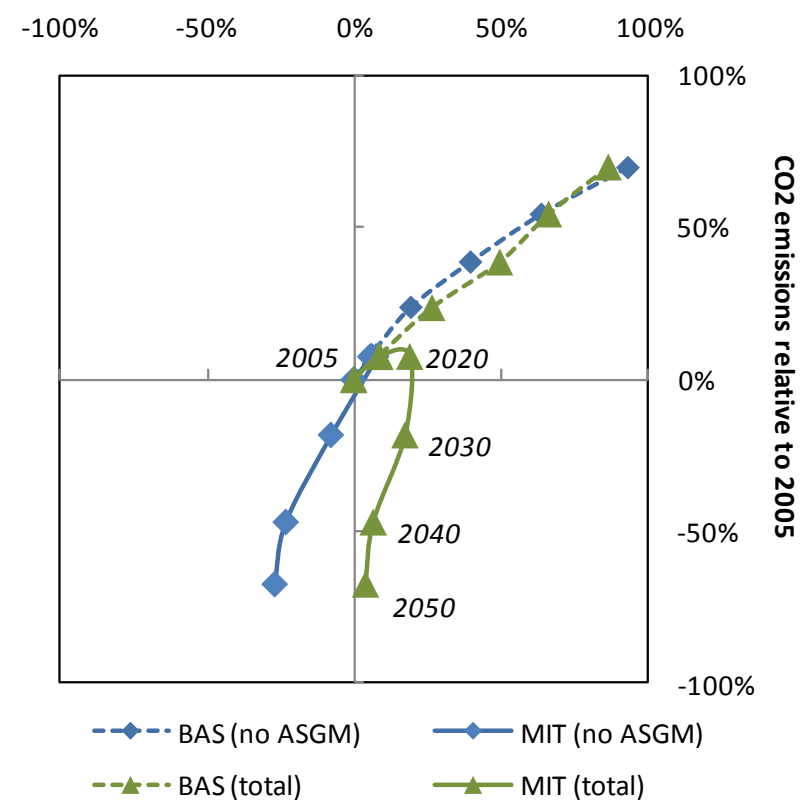

Fig. 3. Reduction of global $\mathrm{Hg}$ emissions relative to the $\mathrm{CO}_{2}$ emission reductions in the Baseline and Mitigation scenarios in comparison to the year 2005 .

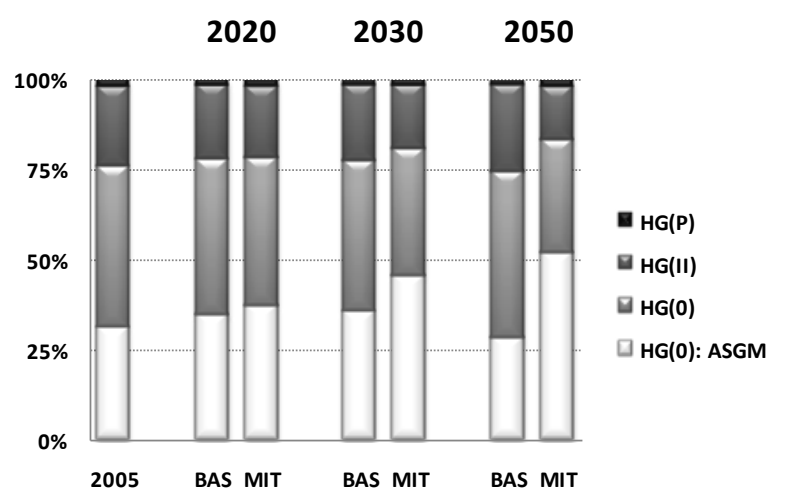

Fig. 4. Share of mercury species in the Baseline and Mitigation scenarios for the period $2005-2050$.

global increase by $70 \%$ relative to 2005 . At the same time, gradual changes in the energy sectors and adoption of emission controls lead to a large decrease in mercury levels in EU-27 and in US, when compared to present. In China and India, however, the assumed penetration of abatement technologies keeps the overall growth in $\mathrm{Hg}$-emissions at a high rate.

In the Mitigation scenario, the global carbon emissions are lower by $70 \%$ relative to the base year. The decrease in $\mathrm{Hg}$-emission becomes to be apparent after the year 2020 and the biggest reduction is achieved in 2050 . Despite a massive decrease in the demand for coal for power generation and reduced industrial coal use, the cuts in $\mathrm{CO}_{2}$ and mercury emissions are not proportional under the scenario assumptions.

Finally, an analysis has been carried out on the impacts of climate policies on the time evolution of 
mercury speciation. As is seen in Figure 4, elemental mercury $\mathrm{Hg}(0)$ is the dominant form of $\mathrm{Hg}$ across all years and scenarios. The share of divalent mercury $\mathrm{Hg}$ (II) increases slightly over time in the Baseline scenario because of air pollution measures and structural changes. On the other hand, the relative share of elemental mercury increases in the Mitigation case since many of the major emission sources for $\operatorname{Hg}(0)$ remain unaffected by the global climate strategies.

\section{Conclusion}

The results of scenario calculations using the GAINS model for anthropogenic mercury emissions indicate significant scope for ancillary benefits made possible through climate policies. Decarbonisation of the global energy system by 2050 results in $\mathrm{Hg}$ emissions lower by half than in the world without GHG-abatement efforts. In general, the largest mercury abatement potential of $80 \%$ has been found in the power generation and industrial sectors relying largely on the coal combustion.

The scope of $\mathrm{Hg}$-emission reduction in different regions depends on the fuel and technology shifts under GHGs constraints, as well as being determined by the rate of adoption of the air quality policies. Because of these factors, the potential for co-benefits is estimated to be higher in fast growing economies of China and India as compared to industrialized regions of EU-27 and US.

Although not shown explicitly in this abstract, the co-benefits for mercury reductions invoked by the climate mitigation can be further accelerated in the case that assumes a full implementation of the best available control technologies. Furthermore, climate mitigation measures appear to be more effective in reducing emissions of divalent mercury as compared to $\mathrm{Hg}(0)$. However, the large extend of uncertainties still have to be addressed in order to enhance the robustness of quantitative co-benefit estimates.

\section{Acknowledgements}

Research presented here has been carried out within the EnerGEO project, funded from the European Community's Seventh Framework Programme.

\section{References}

Amann M, Bertok I, Borken-Kleefeld J, Cofala J, Heyes C, Höglund-Isaksson L, Klimont Z, Nguyen B, Posch M, Rafaj P, Sandler R, Schöpp W, Wagner F, Winiwarter W. Cost-effective control of air quality and greenhouse gases in Europe: Modeling and policy applications. Environmental Modelling \& Software (2006); 26(12):1489-1501.

CEC. (2007) Communication from the commission to the council, the European parliament, the European economic and social committee and the committee of the regions. Limiting Global Climate Change to 2 degrees Celsius. The way ahead for 2020 and beyond. Commission of the European communities, Brussels, Belgium.

Cofala J, Rafaj P, Schöpp W, Klimont Z, Borken-Kleefeld J, Amann M. (2010) Emissions of Air Pollutants for the World Energy Outlook 2010 Energy Scenarios. IIASA, Laxenburg, Austria.

Russ P, Ciscar JC, Saveyn B, Soria A, Szabo L, Van Ierland T, Van Regemorter D, Virdis R. (2009) Economic Assessment of Post-2012 Global Climate Policies. Joint Research Centre of the European Community, Seville, Spain.

van Aardenne JA, Dentener F, Dingenen RV, Maenhout G, Marmer E, Vignati E, Russ P, Szabo L, Raes F (2010) Climate and air quality impacts of combined climate change and air pollution policy scenarios. Joint Research Centre - Institute for Environment and Sustainability, Luxembourg. 